\title{
'First things first': The AMS Review - Sheth Foundation 2020 annual doctoral competition for conceptual articles
}

\author{
Jodie Conduit $^{1} \cdot$ Michael Kleinaltenkamp $^{2}$ \\ Published online: 14 May 2020 \\ (C) Academy of Marketing Science 2020
}

A theoretical contribution is the cornerstone of all doctoral dissertation research. However, while a doctoral thesis usually involves considerable conceptual development, relatively few doctoral students seek to publish conceptual-only articles as compared to empirical articles. In parallel, marketing academia is increasingly calling for conceptual articles that focus on building and extending theory (MacInnis 2011; Jaakkola this issue), and these papers are often highly cited. A conceptual paper is an avenue through which the researcher can critique the existing literature, position their research in an ongoing theoretical conversation, demonstrate their original theoretical contribution to the field, and build the foundation for further research, including empirical research (Barney this issue); all key stages in a doctoral dissertation.

Why then do we not see more conceptual-only papers published from dissertation research? Perhaps some students do not know it is an option; some may not perceive they have the skills or capability; while others just do not know where to begin. Yadav (this issue) advocates that it is imperative that conceptual theory development is placed at the core of the curriculum in doctoral programs, as it shapes the thinking, priorities, and research efforts of new scholars. However, in many doctoral programs, this emphasis is lacking. This Special Section of the AMS Review provides some foundational papers that should form part of all doctoral student education. However, to further encourage more conceptual articles to emerge from doctoral dissertations there remains a need to nurture and showcase the outstanding conceptual articles that doctoral students contribute in marketing.

The AMS Review - Sheth Foundation Annual Doctoral Competition for Conceptual Articles was established to

Jodie Conduit

jodie.conduit@adelaide.edu.au

1 University of Adelaide, Adelaide, Australia

2 Freie Universität Berlin, Berlin, Germany encourage, support and celebrate the conceptual contribution made by doctoral students to the marketing literature. All current, or recently completed, doctoral students are invited to submit a five-page proposal for a conceptual research paper. The competition has three core objectives: 1) to encourage doctoral students to identify and publish impactful conceptual ideas in their research; 2) to help doctoral students connect with leading marketing scholars, and obtain feedback to enhance their conceptual contribution; and 3) to advance theory development in the marketing discipline. Importantly, all students entering this competition receive feedback from leading marketing scholars that will help them to advance their conceptual development towards publication.

In 2020, the competition generated an enthusiastic response from doctoral students, with 34 submissions from across the world including Australia, Brazil, Canada, Finland, Germany, India, Turkey, United Kingdom and the United States. These manuscripts comprised a wide range of conceptual contributions; including manuscripts proposing new conceptual frameworks or models, propositions to support theoretical extensions, and comprehensive syntheses of existing research literature. All proposals that met the criteria for conceptual articles were sent to a set of internationally esteemed marketing scholars, who provided constructive reviews on how to improve the manuscript for publication. Further, the co-chairs reviewed the papers and selected 12 proposals, which have been invited for further development into full articles for consideration for publication by the AMS Review. In addition to the reviewer's comments, the five winners and seven runners-up are invited to take advantage of the opportunity of one or more mentoring sessions with one of the Doctoral Competition Chairs, to further workshop and enhance the conceptual article prior to submission to the AMS Review.

After careful consideration of the proposals by the reviewers and subsequent evaluation by the competition chairs, we selected the most promising five proposals to each receive a US\$600 Award. These winners will be recognized at and invited to present at the next AMS Conference, when it is rescheduled. 
We congratulate the following five winners (in alphabetical order):

Zeynep Müge Güzel "Cleansing the doors of perception: perceptual inaccuracy in marketing relationships", Koç University, Turkey.

Youngtak M. Kim "Corporate Sustainability (CS) and firm performance: a systematic review and topic modeling approach", University of Georgia, USA.

Kerry Manis "AI-enabled marketing capabilities: an exploration through the hierarchy of operant resources (HOR) perspective", Texas Tech University, USA.

Pallav Routh "Demand spillover of add-ons: the role of network homogeneity", University of Texas at San Antonio, USA.

Sajith Siriwardana "Conceptualizing service exclusion through service-dominant logic", University of Tasmania, Australia.
We wish to thank all applicants for their effort and dedication to the development and publishing of conceptual-only articles. Overall, the submissions were excellent. We trust that the feedback received from our dedicated team of reviewers will advance the conceptual development of their doctoral theses and subsequent papers. We hope to see many of them published here in the AMS Review in the future.

\section{Reference}

MacInnis, D. J. (2011). A framework for conceptual contributions in marketing. Journal of Marketing, 75(4), 136-154.

Publisher's note Springer Nature remains neutral with regard to jurisdictional claims in published maps and institutional affiliations. 